\title{
Research on the Evaluation of Innovation Efficiency and Its Influencing Factors in 11 Eastern Coastal Provinces and Cities: Based on Three-stage DEA and Tobit Models
}

\author{
Wang Xie-yong ${ }^{1 \mathrm{a}}$ ChenXiao-xian ${ }^{1 \mathrm{~b}}$ \\ ${ }^{1}$ School of Economics and Management, Dalian University Dalian, China
}

\begin{abstract}
Based on panel data from 2008 to 2017, a BCC model and a DEA-Tobit model based on a threestage DEA method are established to study the regional innovation capabilities and their influencing factors of 11 provinces and cities in the eastern coastal areas of China. The research finds that the innovation efficiency in the eastern coastal areas is still far from the frontier of innovation efficiency, and the low scale efficiency is the main factor restricting its development. In terms of influencing factors of innovation efficiency, improving technological level, optimizing market environment, and expanding enterprise scale can improve regional innovation efficiency, while the irrational expansion of the financial industry will hinder the development of innovation capabilities. Based on the research conclusions, policy suggestions such as actively exerting the effects of industrial agglomeration, deepening the reform of old industrial bases, and optimizing the innovation environment are put forward.
\end{abstract}

\section{INTRODUCTION}

General Secretary Xi Jinping pointed out in the report of the 19th National Congress of the Communist Party of China that China's economy has shifted from a high-speed growth stage to a high-quality development stage, and innovation is the key motivation for achieving highquality development. Only an innovation-driven economy can achieve sustainable high-quality development[1]. Regional innovation capability is one of the important indicators for evaluating regional high-quality development. Research on how to improve the efficiency of regional innovation capability and the factors affecting regional innovation capability has become the focus of scholars' attention.

From the existing literature, the research content of regional innovation mainly focuses on the four major aspects of the main elements of regional innovation, innovation ability evaluation, regional innovation diffusion, and regional innovation strategy. Bai Junhong and Jiang Fuxin (2015) research found that in the process of collaborative innovation, government science and technology funding, the connection between enterprises and universities, and the connection between enterprises and research institutions have a significant positive impact on regional innovation performance, while financial institution funding has a significant negative to influence[2]. Liu Xiulin, Hu Zhijian (2002) analyzed the significance and evolution of China's regional innovation capability research, established a comprehensive innovation capability index system, and made a basic judgment on China's regional innovation capability[3]. Yu Yongze and Liu Dayong (2013) concluded that the innovation efficiency in each stage shows a relatively obvious spatial correlation. Therefore, multiple space panel models and multiple space weight matrix methods were used to analyze the innovation space spillover effect and value chain spillover effect[4]. Hong Yinxing (2013) believes that the innovation-driven development strategy is a systematic project that involves both knowledge innovation and technology innovation, and involves both a fundamental change in the mode of economic development and a major reform of the corresponding economic system[5].

Regional innovation is an important support for China's technological and economic progress. How to use scientific methods to conduct research is very important. At present, China's research methods on regional innovation efficiency can be roughly divided into three categories: statistical analysis, frontier analysis and systems. Analysis. Scholars Li Jing, Tan Qingmei (2010) and others constructed spatial weight matrices from two aspects of geographic characteristics and socioeconomic characteristics, established static and dynamic spatial panel econometric models based on translog production functions, and examined mainland China from 1998 to 2007. Spatial correlation and agglomeration of innovations in 30 provincial regions [6]. Guan Jiancheng, He Ying (2005) applied the two-stage DEA model, using patents as intermediate products, and divided regional innovation activities into technological output stages, economic output stages, and a combination of the two, 
respectively, for the technological effectiveness of innovative activities. Economic effectiveness and comprehensive effectiveness [7]. In the area of applied system science research on regional innovation, $\mathrm{Xu}$ Yulian, Wang Yudong (2011) and other scholars analyzed the interactive coupling relationship between regional scientific and technological innovation and financial science and technology. Establish an evaluation model for the degree of coupling and coordination of regional scientific and technological innovation and technology and finance, and use empirical analysis of the degree of coupling and coordination of provincial and regional statistics in China[8].

By summarizing the previous research results, we find that Chinese scholars have some research on regional innovation efficiency, but there is still room for improvement. First of all, there are few studies on factors affecting regional innovation efficiency in China. Most scholars only use input-output models to obtain the influencing factors have not been further studied, which is obviously lacking. Secondly, in the process of regional innovation research, the data is selected with a small span of years. Most of them only research the innovation efficiency in the past one or two years, and failed to analyze the innovation efficiency. The conclusion is that the overall trend of change is clear. This partial approach is obviously unfair and lacks data support. Therefore, this paper selects the three-stage DEA model, and combines the data of 11 provinces and cities in the eastern coast of China with 2008-2017 to estimate the regional innovation efficiency. The factors affecting the regional innovation efficiency are analyzed using the Tobit model. Finally, the corresponding results are obtained based on the regional innovation analysis results. The conclusion is to provide a useful reference for improving the innovation efficiency of China's eastern coastal areas.

\section{Model DESIGN AND VARIABLES, DATA}

\section{A. Three-stage DEA model}

In 1978, the famous operations researcher A. Charnes, WWCooper [9], etc. proposed the Data Envelopment Analysis (DEA), which is often used to measure the comprehensive efficiency under multiple inputs and multiple outputs. The function form of input and output needs to be set in advance to avoid errors caused by the artificial setting of the function. At the same time, the DEA model is not affected by the data unit. The measurement does not need to be normalized when measuring. Later Fried $(1999,2002)[10,11]$ pointed out that the traditional DEA model did not consider the influence of environmental factors and random noise on the efficiency of decision-making units, so it discussed how to introduce environmental factors and random noise into the DEA model. It is called a three-stage DEA model in China. The key of the three-stage DEA model is how to eliminate environmental factors and random noise in the second stage.

\section{B. Variable selection and data description}

The template is used to format your paper and style the text. All margins, column widths, line spaces, and text fonts are prescribed; please do not alter them. You may note peculiarities. For example, the head margin in this template measures proportionately more than is customary. This measurement and others are deliberate, using specifications that anticipate your paper as one part of the entire proceedings, and not as an independent document. Please do not revise any of the current designations.

\section{1) Variable selection and data description}

Whether using traditional DEA or conducting a threestage DEA analysis, first determine the input and output variables. With reference to previous scholars' research and data availability, this paper makes the following variables selection:

a) Investment indicators. Through research on relevant literature, it can be found that research funding and research staff's input have the greatest impact on regional innovation efficiency. To this end, this article selects the stock of R \& D funding internal expenditure after perpetual inventory method to measure the funding required for innovation. $\mathrm{R} \& \mathrm{D}$ personnel are full-time equivalent to measure the role of technology $R$ \& $D$ personnel on innovation efficiency.

b) Output indicators. From the perspective of innovation output results, the number of patent grants is undoubtedly the most direct indicator of innovation results. In fact, even if the patent application has not been authorized for the innovation results, it can promote the development of innovation capabilities. The number of patent applications accepted as an output variable; considering the market's acceptance of innovation output, the sales revenue of new products intuitively shows the ability of technological innovation to translate into economic benefits, so the sales revenue of new products is also an ideal output index.

c) Envirnmental factor. The main environmental factors affecting the efficiency of regional innovation include the level of the regional economy, the degree of openness to the outside world, the level of government support, and the scale of financial development. The sound development of the regional economy is a necessary factor to enhance the efficiency of regional innovation. Per capita gross domestic product (PGDP) can be eliminated The influence of demographic factors comprehensively reflects the economic development results of a region. At present, all regions are actively attracting investment and formulating various policies to attract foreign investment. This article chooses to use foreign direct investment (PFDI) per capita as a measure of the degree of opening up of a region; the government The ratio of funds to internal expenditure of $\mathrm{R} \& \mathrm{D}$ funds (GOV) indicates the strength of local government support. Government support directly affects the basic conditions of regional innovation and the ability to allocate innovative resources. Financial institutions also have a negligible impact on innovation activities. Value to GDP (FIN) to indicate the level of financial development. 
In summary, the results of the data description are summarized in Table 1, and the statistical characteristics of each input-output data are summarized in Table 2.

Table 1 Summary of sample variables

\begin{tabular}{|c|c|c|}
\hline type & variable & unit \\
\hline \multirow[t]{2}{*}{$\begin{array}{l}\text { Input } \\
\text { indicator }\end{array}$} & $\begin{array}{c}\text { Internal expenditure stock of } \mathrm{R} \& \mathrm{D} \\
\text { funds after perpetual inventory method } \mathrm{X}_{1}\end{array}$ & $\begin{array}{c}\text { Ten thousand } \\
\text { yuan }\end{array}$ \\
\hline & $\mathrm{R} \& \mathrm{D}$ personnel full-time equivalent $\mathrm{X}_{2}$ & Man-year \\
\hline \multirow[t]{2}{*}{ Output indicator } & Revenue from sales of new products $Y_{1}$ & $\begin{array}{c}\text { Ten thousand } \\
\text { yuan }\end{array}$ \\
\hline & $\begin{array}{l}\text { Number of domestic patent applications } \\
\text { acceptedY }\end{array}$ & Pieces \\
\hline \multirow[t]{4}{*}{$\begin{array}{l}\text { Environmental } \\
\text { factor }\end{array}$} & GDP per capita PGDP & $\begin{array}{c}\text { Ten thousand } \\
\text { yuan }\end{array}$ \\
\hline & $\begin{array}{l}\text { Per capita use of foreign direct } \\
\text { investment PFDI }\end{array}$ & $\begin{array}{c}\text { Ten thousand } \\
\text { yuan }\end{array}$ \\
\hline & $\begin{array}{l}\text { Ratio of government funds to internal } \\
\text { expenditures of R \& D funds GOV }\end{array}$ & $\%$ \\
\hline & $\begin{array}{l}\text { Financial industry's value added as a } \\
\text { percentage of GDP FIN }\end{array}$ & $\%$ \\
\hline
\end{tabular}

Table 2 Statistical analysis of innovation input-output indicators in sample regions

\begin{tabular}{c|c|c|c|c}
\hline Variable & Mean & Std. Dev. & Min & Max \\
\hline $\mathrm{X}_{1}$ & 5522362.00 & 4437040.00 & 27465.00 & 20000000.00 \\
$\mathrm{X}_{2}$ & 194324.60 & 147229.20 & 1726.31 & 565287.00 \\
$\mathrm{Y}_{1}$ & 79400000.00 & 74900000.00 & 249245.90 & 349000000.00 \\
$\mathrm{Y}_{2}$ & 128522.90 & 138049.00 & 873.00 & 627834.00 \\
PGDP & 6.37 & 2.61 & 1.72 & 12.90 \\
PFDI & 0.25 & 0.19 & 0.03 & 0.96 \\
GOV & 0.22 & 0.17 & 0.07 & 0.89 \\
FIN & 0.07 & 0.04 & 0.03 & 0.17 \\
\hline
\end{tabular}

2) Data processing.

This article estimates the internal expenditure data of $\mathrm{R} \& \mathrm{D}$ funds in 11 provinces and cities in the eastern coastal areas of China using the perpetual inventory method: $R D K_{i t}=(1-\delta) R D K_{i, t-i}+E_{i t}, R D K_{i t}, R D K_{i, t-}$ 1 representing the $\mathrm{R} \& \mathrm{D}$ capital stock of provinces and cities $\mathrm{i}$ in year $\mathrm{t}$ and year $\mathrm{t}-1, E_{i t}$ represents the $\mathrm{R} \& \mathrm{D}$ expenditures of province $\mathrm{i}$ in the t-year, $\delta$ depreciation rate representing $\mathrm{R} \& \mathrm{D}$ capital stock, set $\delta=15 \%$. Capital stock $R D K_{i 0}=E_{i 0} /(g+\delta), E_{i 0}$ represents the internal expenditure of $\mathrm{R} \& \mathrm{D}$ funds in the initial year. This article sets 2008 as the base period, and g represents the average growth rate.

\section{3) Data Sources}

In view of the availability of data, the data of 11 provinces and cities (Beijing, Tianjin, Hebei, Liaoning, Shanghai, Jiangsu, Zhejiang, Fujian, Shandong, Guangdong, and Hainan) from 2008 to 2017 in the eastern coastal areas of China were selected as the research sample. The basic data comes from websites such as China Statistical Yearbook of Science and Technology, China Statistical Yearbook, and National Bureau of Statistics.

\section{Measurement of Regional InNOVAtion INPUT AND OUTPUT EFFICIENCY BASED ON THREE-STAGE DEA MODEL}

\section{A. The first stage of traditional DEA model analysis of initial efficiency}

\section{1) Eastern Coastal Region's Overall Innovation} Efficiency

Using DEAP2.1 software to measure input-output indicators of innovation efficiency in 11 provinces and cities in the eastern coastal areas of China with inputoriented BCC model, the results are shown in Table 3.

Table 3 The comprehensive efficiency of traditional DEA in the first stage (2008-2017)

\begin{tabular}{c|c|c|c|c|c|c|c|c|c|c|c}
\hline & 2008 & 2009 & 2010 & 2011 & 2012 & 2013 & 2014 & 2015 & 2016 & 2017 & Mean \\
\hline BJ & 0.355 & 0.433 & 0.424 & 0.365 & 0.333 & 0.471 & 0.665 & 0.755 & 0.715 & 0.620 & 0.514 \\
TJ & 1.000 & 1.000 & 1.000 & 1.000 & 0.979 & 1.000 & 0.986 & 0.892 & 0.855 & 0.760 & 0.947 \\
HB & 0.511 & 0.600 & 0.477 & 0.622 & 0.729 & 0.670 & 0.676 & 0.629 & 0.620 & 0.668 & 0.620 \\
LN & 0.517 & 0.686 & 0.646 & 0.723 & 0.739 & 0.780 & 0.797 & 0.757 & 0.679 & 0.674 & 0.700 \\
SH & 1.000 & 0.940 & 0.978 & 1.000 & 0.959 & 0.839 & 0.988 & 0.842 & 0.864 & 0.890 & 0.930 \\
JS & 1.000 & 1.000 & 1.000 & 1.000 & 1.000 & 1.000 & 1.000 & 0.977 & 0.909 & 0.827 & 0.971 \\
ZJ & 0.976 & 1.000 & 0.922 & 1.000 & 1.000 & 1.000 & 1.000 & 1.000 & 1.000 & 0.861 & 0.976 \\
FJ & 0.683 & 1.000 & 0.755 & 0.982 & 0.978 & 0.805 & 0.809 & 0.974 & 1.000 & 0.998 & 0.898 \\
SD & 0.741 & 0.987 & 0.942 & 1.000 & 1.000 & 0.961 & 1.000 & 0.955 & 0.952 & 0.964 & 0.950 \\
GD & 0.789 & 0.966 & 1.000 & 0.975 & 0.942 & 0.868 & 0.907 & 0.885 & 0.979 & 1.000 & 0.931 \\
HN & 1.000 & 1.000 & 1.000 & 1.000 & 1.000 & 1.000 & 1.000 & 1.000 & 0.915 & 1.000 & 0.992 \\
\hline Mean & 0.779 & 0.874 & 0.831 & 0.879 & 0.878 & 0.854 & 0.893 & 0.879 & 0.863 & 0.842 & 0.857 \\
\hline
\end{tabular}

From the overall innovation efficiency of the eastern coastal areas, it can be concluded that the overall efficiency of the eastern coastal innovation varies from 0.78 to 0.89 from 2008 to 2017 without considering the influence of environmental factors and random factors, and the maximum innovation comprehensive efficiency reached 0.893 in 2014. In 2008, the lowest innovation efficiency was 0.779 , showing an overall increase in fluctuations. In terms of the innovation efficiency of the 11 provinces and cities along the eastern coast, in order to more intuitively compare the innovation efficiency levels of various regions, Table 3 lists the average innovation efficiency of the 11 provinces and cities in the last ten years. From this table, we can see that Hainan and Zhejiang, Jiangsu, and Shandong ranked among the top four innovation efficiency levels from 2008 to 2017, and the average innovation efficiency was higher than 0.95 . Among them, Hainan Province reached the frontier of innovation efficiency up to a total of 9 times, which is not in line with expectations, probably due to statistics It is caused by incorrect data or inconsistent data statistics. Beijing, Hebei, and Liaoning are lagging behind in 11 provinces and cities. The overall innovation efficiency has not reached the average level. The innovation efficiency is not ideal. The innovation capacity needs to be further improved. The results of traditional DEA analysis show that there is a large gap in innovation efficiency between 
regions and an uneven distribution of innovation capabilities.

\section{2) Innovation Efficiency Based on the Three} Economic Circles

The three-stage DEA analysis can also decompose the comprehensive efficiency into pure technical efficiency and scale efficiency. In order to further study the difference in innovation efficiency in the eastern coastal areas, this article classifies the 11 eastern coastal provinces and cities according to China's three economic circles. That is, the Bohai Rim Economic Circle(BH) includes Liaoning, Hebei, Beijing, Tianjin, Shandong, the Yangtze River Delta economic circle(YT) includes Jiangsu, Zhejiang, and Shanghai, and the Pan-Pearl River Delta economic circle(PP) includes Guangdong, Fujian, and Hainan. The results are shown in Table 4.

Table 4 Traditional DEA analysis results by economic circle

\begin{tabular}{|c|c|c|c|c|c|c|c|c|c|c|c|c|}
\hline & EC & 2008 & 2009 & 2010 & 2011 & 2012 & 2013 & 2014 & 2015 & 2016 & 2017 & Mean \\
\hline \multirow{4}{*}{ Crs } & BH & 0.625 & 0.741 & 0.698 & 0.742 & 0.756 & 0.776 & 0.825 & 0.798 & 0.764 & 0.737 & 0.746 \\
\hline & YT & 0.992 & 0.980 & 0.967 & 1.000 & 0.986 & 0.946 & 0.996 & 0.940 & 0.924 & 0.859 & 0.959 \\
\hline & PP & 0.824 & 0.989 & 0.918 & 0.986 & 0.973 & 0.891 & 0.905 & 0.953 & 0.965 & 0.999 & 0.940 \\
\hline & Mean & 0.814 & 0.903 & 0.861 & 0.909 & 0.905 & 0.871 & 0.909 & 0.897 & 0.884 & 0.865 & 0.882 \\
\hline \multirow{4}{*}{ Vrs } & $\mathrm{BH}$ & 0.655 & 0.749 & 0.719 & 0.749 & 0.771 & 0.793 & 0.842 & 0.824 & 0.791 & 0.767 & 0.766 \\
\hline & YT & 1.000 & 0.995 & 0.974 & 1.000 & 0.990 & 0.957 & 0.999 & 0.953 & 0.961 & 0.869 & 0.970 \\
\hline & PP & 1.000 & 1.000 & 0.923 & 1.000 & 1.000 & 0.961 & 0.948 & 1.000 & 1.000 & 1.000 & 0.983 \\
\hline & Mean & 0.885 & 0.915 & 0.872 & 0.916 & 0.920 & 0.903 & 0.929 & 0.926 & 0.917 & 0.879 & 0.906 \\
\hline \multirow{4}{*}{ Scal } & $\mathrm{BH}$ & 0.953 & 0.988 & 0.971 & 0.988 & 0.976 & 0.978 & 0.978 & 0.967 & 0.963 & 0.960 & 0.972 \\
\hline & YT & 0.992 & 0.985 & 0.992 & 1.000 & 0.996 & 0.988 & 0.997 & 0.985 & 0.963 & 0.989 & 0.989 \\
\hline & PP & 0.824 & 0.989 & 0.994 & 0.986 & 0.973 & 0.927 & 0.955 & 0.953 & 0.965 & 0.999 & 0.957 \\
\hline & Mean & 0.923 & 0.987 & 0.986 & 0.991 & 0.982 & 0.964 & 0.977 & 0.968 & 0.964 & 0.983 & 0.973 \\
\hline
\end{tabular}

As can be seen from Table 5, the average value of the comprehensive innovation efficiency of the three major economic circles from 2008 to 2017 was 0.882 , and the level of efficiency increased in fluctuations. Among them, the innovation efficiency of the Bohai Rim Economic Circle was the lowest at 0.746 , and the comprehensive innovation of the Yangtze River Delta economic circle. The highest efficiency is 0.959 ; the average value of pure technical efficiency is 0.906 , and there is still a certain distance from the frontier of efficiency. The highest pure technical efficiency value of the Pan-Pearl River Delta Economic Circle is 0.983 , and the lowest pure technical efficiency value of the Bohai Economic Circle is 0.766; The average value is 0.973 , which is at the forefront of efficiency, with little difference between the three major economic circles. In summary, the scale efficiency value is higher than the pure technology efficiency value as a whole, and the management capacity and innovative technology level in the eastern coastal areas need to be improved.

\section{B. Second stage SFA-like regression removes environmental factors and statistical noise}

Although the above traditional DEA model can make a preliminary estimate of the innovation efficiency of the eastern coastal areas, due to the vastness of China and the large gap in economic development levels and innovation capabilities between regions, innovation efficiency in different regions will inevitably be disturbed by environmental and other external factors Therefore, it is necessary to use SFA model to eliminate the influence of environmental factors and random interference on input variables.

Taking the slack variable of $\mathrm{R} \& \mathrm{D}$ funding internal expenditure and R \& D personnel full-time equivalent as input as the explanatory variable, the regional economic level, the degree of openness to the outside world, government support, and the size of financial development as explanatory variables, regress them separately using Frontier 4.1 software. The estimation results are shown in Table 5.

Table 5 Similar SFA-like estimation results in the second stage (20082017)

\begin{tabular}{|c|c|c|c|c|}
\hline & $\begin{array}{c}\text { Slack Variables } \\
\text { in the } \\
\text { Internal } \\
\text { Expenditures } \\
\text { of R \& D Funds }\end{array}$ & $\mathrm{t}$ test value & $\begin{array}{l}\text { R \& D personnel } \\
\text { full-time } \\
\text { equivalent } \\
\text { slack variable }\end{array}$ & t test value \\
\hline $\mathrm{C}$ & $-3359518.30^{* * *}$ & -3359515.40 & $-48427.72^{* * *}$ & -340.32 \\
\hline PGDP & $-26418.36^{* * *}$ & -26418.10 & $3059.77^{* * *}$ & 6.04 \\
\hline PFDI & $-2356525.60^{* * *}$ & -2356525.60 & $-58247.64^{* * *}$ & -2647.62 \\
\hline GOV & $5904243.30^{* * *}$ & 5904218.70 & $81179.08^{* * *}$ & 509.10 \\
\hline FIN & $31227259.00^{* * *}$ & 31227258.00 & $213331.62^{* * *}$ & 10106.34 \\
\hline$\sigma^{2}$ & $\begin{array}{c}636351390000.0 \\
0^{* * *}\end{array}$ & $\begin{array}{c}636351390000 \\
00\end{array}$ & $127120140.00^{* * *}$ & $\begin{array}{c}127120100 \\
.00\end{array}$ \\
\hline$\gamma$ & $0.86^{* * *}$ & 43.16 & $0.78^{* * *}$ & 24.65 \\
\hline LR & $105.05^{* * *}$ & & $62.43^{* * *}$ & \\
\hline
\end{tabular}

The results showed that the LR test passed the 1\% significance level test, which proved that the SFA regression was reasonable. The $\sigma 2$ value and the $\gamma$ value were significant at the $1 \%$ level, and the $\gamma$ values were 0.86 and 0.78 , respectively, which were greater than 0.5 . Factors other than the influence of slack variables can also cause investment slack, so it is necessary to eliminate environmental and random factors.

From the perspective of the SFA regression coefficients, the coefficient estimation results have passed the $1 \%$ test and are very significant. The regression coefficient describes the impact of environmental variables on the input relaxation variables. When the regression coefficient is positive, it means that increasing the environmental variables will increase the input relaxation values. That is, it will reduce the utilization efficiency of input elements and increase input waste. On the contrary, when the coefficient is negative, it means that increasing environmental variables will weaken the slack variables of input, that is, reduce input waste.

1) Regional economic level. This variable has a negative regression coefficient on the slack value of the internal expenditure stock of R \& D funds, that is, an increase in the per capita GDP of the input region will promote the use of scientific research funds, which can be attributed to the spillover effect of regional economic development, and the higher the level of regional 
economic development, The better the corresponding infrastructure, innovation environment, industrial structure, etc., the corresponding will increase the use of investment funds and reduce waste; the coefficient of this variable's full-time equivalent relaxation value of $R \& D$ personnel is positive, indicating that per capita The increase of GDP will reduce the use efficiency of human capital, which is not in line with expectations. This may be caused by the unreasonable structure of regional scientific research personnel, and staffing reform and upgrading should be actively promoted.

2) Degree of opening up. The slack regression coefficients of this variable for the funding and personnel input variables are both negative, indicating that expanding the degree of opening up can reduce the amount of regional innovation investment, reduce resource waste, and promote the increase of regional innovation efficiency.

3) Government support. The coefficient of the slack value of this variable for capital and personnel investment is positive, indicating that government investment in scientific research funds increases R \& D expenditure and personnel waste, and reduces regional innovation efficiency. It can be understood that the government's blindly increasing capital investment may cause Redundancy of funds and personnel has resulted in mismatched resources and reduced innovation output.

4) Scale of financial development. A positive regression coefficient indicates that the development of the financial industry cannot improve the utilization rate of R \& D funds and personnel. It may be because of the complex relationship between financial development and regional innovation. The expansion of financial scale has a certain degree of regional innovation efficiency. The crowd-out effect should improve the quality of financial development at a reasonable financial scale and promote the innovation and development of regional economy.

\section{DEA Efficiency Analysis of Input Variables after Phase III Adjustment}

1) Changes in the overall innovation efficiency of the eastern coastal areas

According to the analysis results of the second stage, it was found that environmental factors will indeed affect regional innovation efficiency. Re-adjust the adjusted input variables by DEAP 2.1 software for DEA analysis. The efficiency after excluding environmental factors and random interference is obtained. The results are shown in Table 6.

Table 6 Comprehensive innovation efficiency measured by DEA after the third stage adjustment (2008-2017)

\begin{tabular}{c|l|l|l|l|l|l|l|l|l|l|l}
\hline & 2008 & 2009 & 2010 & 2011 & 2012 & 2013 & 2014 & 2015 & 2016 & 2017 & Mean \\
\hline BJ & 0.499 & 0.546 & 0.518 & 0.443 & 0.396 & 0.541 & 0.725 & 0.805 & 0.807 & 0.642 & 0.592 \\
TJ & 0.653 & 0.686 & 0.623 & 0.638 & 0.637 & 0.733 & 0.669 & 0.630 & 0.650 & 0.527 & 0.645 \\
HB & 0.331 & 0.323 & 0.284 & 0.355 & 0.410 & 0.446 & 0.465 & 0.460 & 0.445 & 0.465 & 0.398 \\
LN & 0.458 & 0.564 & 0.445 & 0.502 & 0.490 & 0.579 & 0.542 & 0.519 & 0.467 & 0.445 & 0.501 \\
SH & 1.000 & 0.957 & 0.891 & 0.973 & 0.860 & 0.858 & 0.853 & 0.776 & 0.777 & 0.763 & 0.871 \\
JS & 1.000 & 1.000 & 1.000 & 1.000 & 1.000 & 1.000 & 1.000 & 1.000 & 0.968 & 0.869 & 0.984 \\
ZJ & 1.000 & 1.000 & 0.867 & 0.915 & 0.859 & 1.000 & 0.965 & 1.000 & 1.000 & 0.845 & 0.945 \\
FJ & 0.491 & 0.470 & 0.409 & 0.479 & 0.433 & 0.462 & 0.425 & 0.552 & 0.708 & 0.590 & 0.502
\end{tabular}

\begin{tabular}{l|l|l|l|l|l|l|l|l|l|l|l}
$\mathrm{SD}$ & 0.858 & 1.000 & 0.929 & 1.000 & 1.000 & 1.000 & 0.965 & 0.926 & 0.891 & 0.869 & 0.944
\end{tabular} \begin{tabular}{l|l|l|l|l|l|l|l|l|l|l|l}
$\mathrm{GD}$ & 0.942 & 1.000 & 1.000 & 1.000 & 0.983 & 1.000 & 0.954 & 1.000 & 1.000 & 1.000 & 0.988
\end{tabular} \begin{tabular}{l|l|l|l|l|l|l|l|l|l|l|l}
$\mathrm{HN}$ & 0.036 & 0.026 & 0.037 & 0.044 & 0.040 & 0.047 & 0.041 & 0.049 & 0.050 & 0.056 & 0.043 \\
\hline
\end{tabular} \begin{tabular}{l|l|l|l|l|l|l|l|l|l|l|l}
\hline Mean & 0.661 & 0.688 & 0.637 & 0.668 & 0.646 & 0.697 & 0.691 & 0.702 & 0.706 & 0.643 & 0.674 \\
\hline
\end{tabular}

Through Table 6, it can be found first that the change law of innovation efficiency is basically the same as before the adjustment, showing a law of fluctuation, but the average value of the innovation efficiency in the eastern coastal areas is less than the unadjusted result. Regional innovation efficiency brings a positive impact, but it will reduce efficiency after elimination. Judging from the ranking of provinces, Guangdong, Jiangsu, Zhejiang, and Shandong are the top four regions for adjusted regional innovation efficiency, and the last three provinces are Hainan, Hebei, and Liaoning.

In order to more intuitively analyze the changes in the overall innovation efficiency of the 11 provinces and cities in the eastern coastal region after adjustment, this article will make the change rule before and after adjustment as Figure 1. The results are as follows:

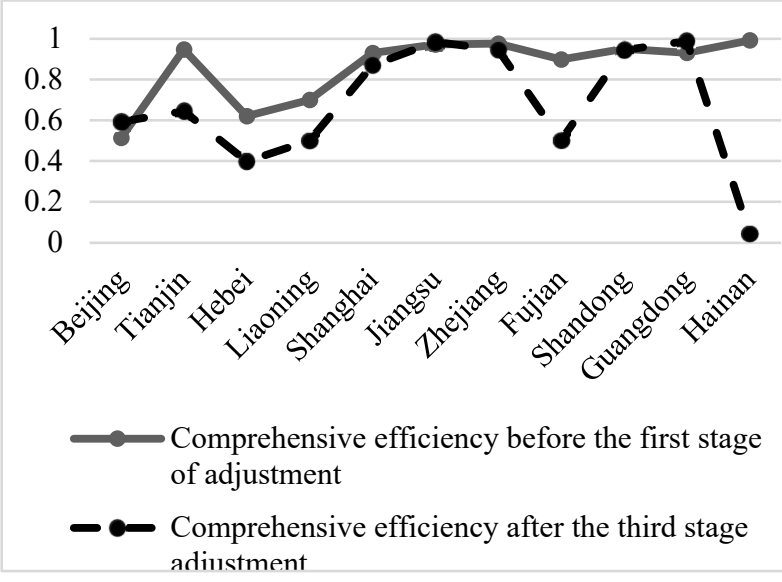

Figure 1 Changes in the mean value of the 11 provinces and cities in the eastern coastal areas before and after the adjustment of the comprehensive innovation efficiency

As can be seen from Figure 1, compared to before the adjustment, only Guangdong, Jiangsu, and Beijing improved their overall innovation efficiency after excluding environmental variables and random interference, indicating that the environmental factors in these three provinces have reduced the development of their innovation capabilities, rather than The management level is not enough, and the overall innovation efficiency of the remaining provinces and cities have declined to varying degrees. The most obvious decline is Hainan and Fujian. The comprehensive efficiency value of Hainan has dropped from 0.992 to 0.043 before adjustment, and Fujian has fallen from 0.898 to 0.502 . The improvement of innovation efficiency in these areas is due to the environment in which these provinces and cities are located, and the management level is not high, and scientific research resources cannot be used to the maximum extent.

2) Changes in innovation efficiency based on the three economic circles

In order to better analyze the differences in innovation efficiency between regions, this article divides the adjusted DEA efficiency analysis results of the third stage 
into three economic circles. The results are shown in Table 7.

Table 7 Adjusted DEA analysis results by economic circle

\begin{tabular}{c|c|c|c|c|c|c|c|c|c|c|c|c}
\hline & EC & 2008 & 2009 & 2010 & 2011 & 2012 & 2013 & 2014 & 2015 & 2016 & 2017 & Mean \\
\hline \multirow{5}{*}{ Crs } & BH & 0.560 & 0.624 & 0.560 & 0.588 & 0.587 & 0.660 & 0.673 & 0.668 & 0.652 & 0.590 & 0.616 \\
& YT & 1.000 & 0.986 & 0.919 & 0.963 & 0.906 & 0.953 & 0.939 & 0.925 & 0.915 & 0.826 & 0.933 \\
& PP & 0.490 & 0.499 & 0.482 & 0.508 & 0.485 & 0.503 & 0.473 & 0.534 & 0.586 & 0.549 & 0.511 \\
\hline & Mean & 0.683 & 0.703 & 0.654 & 0.686 & 0.659 & 0.705 & 0.695 & 0.709 & 0.718 & 0.655 & 0.687 \\
\hline \multirow{5}{*}{ Vrs } & BH & 0.816 & 0.899 & 0.873 & 0.864 & 0.875 & 0.909 & 0.930 & 0.952 & 0.950 & 0.924 & 0.899 \\
& YT & 1.000 & 1.000 & 0.996 & 1.000 & 1.000 & 1.000 & 1.000 & 1.000 & 1.000 & 0.936 & 0.993 \\
& PP & 0.971 & 0.980 & 0.956 & 0.980 & 0.981 & 0.969 & 0.970 & 0.981 & 0.989 & 0.967 & 0.974 \\
\hline & Mean & 0.929 & 0.960 & 0.942 & 0.948 & 0.952 & 0.959 & 0.967 & 0.978 & 0.979 & 0.942 & 0.956 \\
\hline \multirow{5}{*}{ Scal } & BH & 0.681 & 0.683 & 0.627 & 0.667 & 0.657 & 0.717 & 0.717 & 0.698 & 0.681 & 0.635 & 0.676 \\
& YT & 1.000 & 0.986 & 0.923 & 0.963 & 0.906 & 0.953 & 0.939 & 0.925 & 0.915 & 0.887 & 0.940 \\
& PP & 0.505 & 0.509 & 0.502 & 0.518 & 0.494 & 0.519 & 0.487 & 0.545 & 0.594 & 0.570 & 0.524 \\
\hline & Mean & 0.729 & 0.726 & 0.684 & 0.716 & 0.686 & 0.729 & 0.715 & 0.723 & 0.730 & 0.697 & 0.713 \\
\hline
\end{tabular}

The adjusted DEA efficiency value has changed greatly. As a whole, the average innovation efficiency of the three major economic circles has decreased from 0.882 to 0.687 , the pure technical efficiency value has increased from 0.906 to 0.956 , and the scale efficiency has decreased from 0.973 to 0.713 . From the perspective of the economic circle, the adjusted innovation value of the Yangtze River Delta economic circle ranks first in terms of comprehensive efficiency, pure technical efficiency, and scale efficiency. The comprehensive innovation efficiency in the Pan-Pearl River Delta region is mainly affected by scale efficiency, ranking last.

In order to more intuitively compare the efficiency of the third stage DEA with the efficiency of the first stage, this article further categorizes the innovation efficiency before and after adjustment according to the three major economic circles. The results are shown in Figure 2.

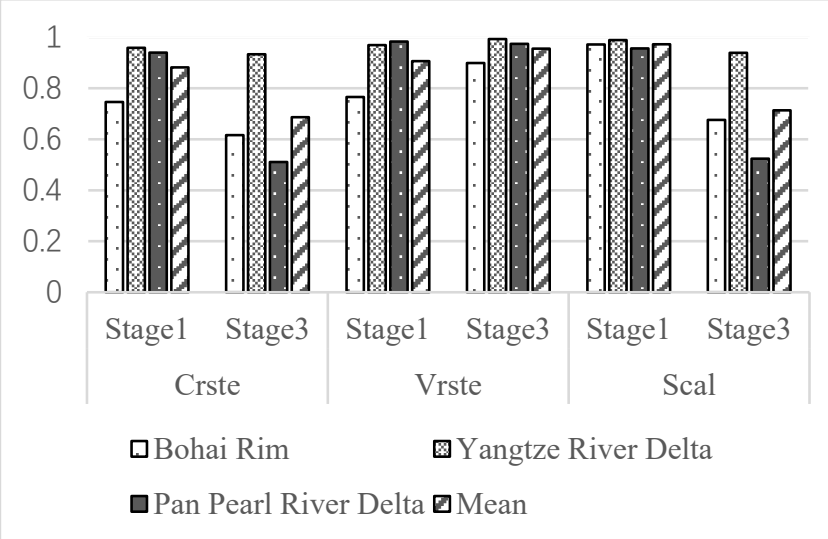

Figure 2 Mean change before and after adjustment of innovation efficiency by economic circle

From the observation in Figure 2, it can be found that the efficiency average polyline representing the Yangtze River Delta economic circle is basically above all polylines. This may be because the economic foundation of the Yangtze River Delta region is good, and innovation and entrepreneurship activities have been placed at the core of strategic development. The high level of technology provides the basic guarantee for the development of innovation capabilities. The pan-Pearl River Delta economic circle has the largest fluctuations in the polyline, which indicates that the innovation efficiency of the Pan-Pearl River Delta region is greatly affected by the environment. Comprehensive analysis shows that the level of pure technical efficiency is always high, and the level of scale efficiency fluctuates the most after excluding environmental variables and random disturbances. This further illustrates that low scale innovation efficiency is an important reason for restricting the improvement of comprehensive innovation efficiency. In the future, it is necessary to actively expand the scale of scientific and technological innovation to achieve resource Centralized management and configuration.

\section{Calculation and Analysis of INFLUENCING FACTORS OF REGIONAL INNOVATION EFFICIENCY BASED ON TOBIT MODEL}

From the analysis results in the previous section, we can see that there is a large regional gap in innovation efficiency among the 11 provinces and cities along the eastern coast of China. However, the specific reasons for the gap in regional innovation efficiency need to be further explored. Innovation efficiency values are between $0-1$, so ordinary least squares cannot be selected for regression. Tobit regression model proposed by Tobin (1958) [12] needs to be selected.

\section{A. Index selection and related description}

This article uses the regional comprehensive innovation efficiency value calculated by the BCC model as the explanatory variable, selects five different types of environmental factors as explanatory variables to establish the Tobit model, and analyzes the impact of environmental factors on the innovation efficiency of the eastern coastal areas of China. The specific formula is as follows:

$$
\begin{array}{r}
\text { crste }_{i t}=\beta_{0}+\beta_{1} \text { tech }_{i t}+\beta_{2} \text { debt }_{i t}+\beta_{3} u n e_{i t}+ \\
\beta_{4} \text { tot }_{i t}+\beta_{5} \text { size }_{i t}+\mu_{i t}
\end{array}
$$

In formula (1), $i$ is the province / city area; $t$ is the year; $\beta_{0}$ is a constant term; $\beta_{1-} \beta_{5}$ are coefficients to be estimated; $\mu$ is a random interference term; tech indicates the number of patent applications granted and reflects the technical level; debt represents loans from banking financial institutions and reflects financial developments; une indicates the registered unemployment rate of provinces and cities, reflecting the employment situation in the region; tot indicates the total investment in fixed assets in the whole society, reflecting the market environment; size indicates the average assets of industrial enterprises above designated size and reflects the size of the enterprise. The results of the statistical description of the variables are shown in Table 8.

Table 8 Statistical analysis of variable indicators

\begin{tabular}{l|l|l|l|l}
\hline Variable & Mean & Std. Dev. & Min & Max \\
\hline
\end{tabular}




\begin{tabular}{c|c|c|c|c}
\hline tech & 73035.43 & 76886.58 & 341 & 332652 \\
debt & 39524.4 & 25760.87 & 1383.47 & 126032 \\
une & 3.148727 & 0.7650593 & 1.2 & 4.4 \\
tot & 17002.14 & 13100.95 & 705.4233 & 55202.72 \\
size & 30009.15 & 24944.21 & 6044.403 & 142326.7 \\
\hline
\end{tabular}

\section{B. Tobit model establishment}

According to formula (1), use Stata 15.1 software to estimate the model. The results are shown in Table 9.

Table 9 Estimation results of Tobit model for the factors affecting innovation efficiency in China's eastern coastal areas from 2008 to 2017

\begin{tabular}{c|c|c|c}
\hline $\begin{array}{c}\text { Explanatory } \\
\text { variables }\end{array}$ & Coefficient & $\begin{array}{c}\text { Standard } \\
\text { deviation }\end{array}$ & P value \\
\hline$C$ & $0.58611080^{* * *}$ & 0.15033390 & 0.000 \\
tech & $0.00000204^{* * *}$ & 0.00000058 & 0.000 \\
debt & $-0.00000748^{* * *}$ & 0.00000181 & 0.000 \\
une & 0.03231750 & 0.03235650 & 0.318 \\
tot & $0.00000475^{* *}$ & 0.00000199 & 0.017 \\
size & $0.00000243^{* * *}$ & 0.00000070 & 0.000 \\
\hline Note: $* * * \mathrm{p}<0.01, * * \mathrm{p}<0.05, * \mathrm{p}<0.1$ &
\end{tabular}

1) Impact of technical level. The regression coefficient of this variable is positive and passed the $1 \%$ significance level test, which indicates that more patent application authorizations will promote the improvement of regional innovation efficiency. The improvement of regional innovation efficiency lies in the improvement of independent innovation capabilities and the development of science and technology. Is the source of power to promote innovation.

2) Financial developments. The secondary indicator of capital flow is that the balance of various loans of banking financial institutions is negatively correlated with the overall innovation efficiency and is significant at the level of $1 \%$, indicating that the development of the financial industry will inhibit the improvement of innovation efficiency to a certain extent. The reason may be that the efficiency of regional capital allocation is not high, and the financial industry structure needs to be further optimized and upgraded to reduce the redundancy and waste of funds.

3) Regional employment situation. This variable does not pass the significance test and is positively related to innovation efficiency, indicating that the increase in regional unemployment rate will promote the improvement of innovation efficiency but the effect is not large. This result may seem difficult to understand, but if you think about it carefully, it is not difficult to find that the unemployment rate The increase reflects to a certain extent the current market competition in China, increased requirements for personnel quality, increased requirements for innovative technological capabilities, obvious survival of the fittest mechanism, and enterprises gradually eliminated redundant personnel, thereby increasing personnel utilization to a certain extent. To promote the improvement of innovation efficiency.
4) Market environment impact. The variable representing the market environment indicator has a significant positive elasticity estimate. Passing the 5\% significance level test, it shows that the increase in the total fixed asset investment of the whole society is conducive to the development of regional innovation capabilities. The economic development level in the eastern coastal areas of China is good, and The development is more balanced, the more mature the market environment, the higher the regional innovation efficiency.

5) Enterprise size impact. This variable passes the $1 \%$ significance level test and has a positive impact on innovation efficiency. The larger the scale of an enterprise, the easier it is to realize the benefits of economies of scale, which is conducive to the economic transformation of innovation results, thereby stimulating the development of regional innovation capabilities.

\section{Conclusions AND COUNTERMEASURES}

\section{A. In conclusion}

On the basis of summing up previous research, based on provincial (municipal) level panel data, a BCC-based DEA-Tobit model is established. The innovation efficiency and its influencing factors of 11 provinces and cities in the eastern coastal areas of China are studied:

First, there is still a certain gap between the overall innovation efficiency of the eastern coastal areas of China and the frontier. From a longitudinal comparison, the overall efficiency value of the eastern coastal areas increased from fluctuations from 2008 to 2017. From a horizontal analysis, Jiangsu, Zhejiang, and Shandong the regional innovation efficiency is relatively high, the comprehensive innovation capabilities of Hebei and Liaoning are low, and the innovation efficiency varies greatly between regions.

Second, from the perspective of the economic circle, the Yangtze River Delta economic circle ranks first among the three major economic circles in terms of comprehensive innovation efficiency, pure technical efficiency, and scale efficiency. This matches its economic development. The environmental impact is large, and the stability of innovation capacity needs to be strengthened. The low scale efficiency of the three major economic circles is the main factor restricting the improvement of innovation efficiency.

Third, at the level of influencing factors, raising the level of science and technology, creating a good market environment, and actively expanding the size of enterprises have a significant positive impact on improving the efficiency of comprehensive innovation. Financial development has a significant negative impact on the efficiency of comprehensive innovation. Attention should be paid to actively improving innovation capabilities at a reasonable scale of financial development.

\section{B. Suggestions}

Based on the above research results, in order to further promote the implementation of innovation-driven 
strategies in coastal areas and improve regional innovation efficiency, this article proposes:

The first is to actively bring into play the role of industrial agglomeration and market concentration in promoting regional innovation capabilities and achieve economies of scale. After excluding environmental variables, the scale efficiency value has dropped significantly, which has become the main factor restricting the development of innovation efficiency in the three major economic circles in the eastern coastal areas of China. Therefore, each region should actively carry out innovation industry planning and construction, implement differentiated innovation development policies, and integrate and optimize. Regional innovation resources, which in turn form an innovation industry cluster, reduce waste of resources, and achieve economies of scale, thereby driving the improvement of comprehensive innovation efficiency.

The second is to deepen the reform of old industrial bases in an all-round way, and move towards new industrial bases through innovative breakthroughs. It is not difficult to find through the calculation of regional innovation efficiency that the old industrial bases represented by Liaoning and Hebei have low innovation efficiency, and their inherent industrialization structure cannot adapt to market changes in the new situation. The relatively backward technological level leads to low resource utilization the overall innovation efficiency ranks behind. To this end, it is necessary to increase investment in scientific and technological innovation, promote the improvement of equipment manufacturing quality and efficiency, cultivate the ability of independent innovation of the industry, accelerate the transformation and upgrading of enterprises, and improve regional core competitiveness.

The third is to optimize the construction of regional innovation environment and encourage the development of innovation practice. Studies have shown that environmental factors have a significant impact on regional innovation efficiency, so regions need to increase marketization and strengthen infrastructure construction, improve the financial environment, rationally improve the innovation investment and financing system, and formulate strategic plans for the introduction of high-level talents for innovation. The development of science and technology provides strong support for talents and promotes the enhancement of innovation capacity in the region.

\section{REFERENCESS}

[1] Jin Bei.Study on the "High-Quality Development" Economics. [J]. China Industrial Economics, 2018(04):5-18.

[2] Bai Junhong, Jiang Fuxin. Collaborative innovation, spatial correlation and regional innovation performance $[\mathrm{J}]$. Economic Research Journal, 2015,50(07):174-187.

[3] Liu Xielin, Hu Zhijian. The pattern of China regional innovation capability and its implication [J]. Studies in Science of Science, 2002(05):550-556.

[4] Yu Yongze, Liu Dayong. The Effect of the Space Outflow of China's Regional Innovation and the Effect of the Outflow of Value Chanins: A Study, from the Perspective of the Innovative Value Chain, on the Model of the Panel of Multidimentsional Space[J]. Management World, 2013(07):6-20.
[5] Hong Yinxing. On the innovation-driven economic development [J]. Economist, 2013(01):5-11.

[6] Li Jing, Tan Qingmei, Bai Junhong. Spatial Econometric Analysis of Regional Innovative Production in China-An Empirical Study Based on Static and Dynamic Spatial Panel Models [J]. Management World, 2010(07):43-55.

[7] Guan Jiancheng, He Ying. The performance of Chinese regional innovation system evaluation based on data envelopment analysis [J]. Studies in Science of Science, 2005(02):265-272.

[8] Xu Yulian, Wang Yudong, Lin Yan. Research on Coupling Coordinated Degree Evaluation of Regional Sci-tech Innovation and Sci-tech Finance [J]. Science of Science and Management of S.\& T., 2011,32(12):116-122.

[9] CHARNES A, COOPER W W, RHODES E. Measuring the efficiency of decision making units[J]. European Journal of Operational Research, 1978.

[10] FRIED H O, YAISAWARNG S S S A. Incorporating the Operating Environment into a Nonparametric Measure of Technical Efficiency[J]. Journal of Productivity Analysis, 1999.

[11] FRIED H O, LOVELL C A K, SCHMIDT S S, et al. Accounting for Environmental Effects and Statistical Noise in Data Envelopment Analysis[J]. Journal of Productivity Analysis, 2002.

[12] TOBIN, JAMES. Estimation of Relationships for Limited Dependent Variables[J]. Econometrica, 1958,26(1):24-36. 